\title{
Navigated focal laser photocoagulation for central serous chorioretinopathy
}

This article was published in the following Dove Press journal:

Clinical Ophthalmology

18 August 2014

Number of times this article has been viewed

\author{
Jay Chhablani ${ }^{1}$ \\ Padmaja Kumari Rani' \\ Annie Mathai' \\ Subhadra Jalali' \\ Igor Kozak ${ }^{2}$
}

'Srimati Kanuri Santhamma Vitreo-Retina Service, L V Prasad Eye Institute, Hyderabad, India; ${ }^{2}$ Division of Vitreoretinal Diseases and Surgery, King Khaled Eye Specialist Hospital, Riyadh, Kingdom of Saudi Arabia
Correspondence: Jay Chhablani L V Prasad Eye Institute, L V Prasad Marg, Banjara Hills, Hyderabad 500034, India

Tel $+9|40306| 2607$

Fax $+9|402354827|$

Email jay.chhablani@gmail.com
Background and objective: To assess the efficacy of navigated laser (Navilas $\left.{ }^{\circledR}\right)$ treatment for central serous chorioretinopathy.

Materials and methods: Prospective study included 16 eyes of 15 subjects with nonresolving central serous chorioretinopathy. Fluorescein-angiography guided Navilas ${ }^{\circledR}$ treatment was performed. Pre- and posttreatment best-corrected visual acuity, pre- and posttreatment central macular thickness, number of leaks on fluorescein angiography, and various treatment parameters were analyzed. Pain experience was evaluated using the visual analog pain scale.

Results: Sixteen eyes from 15 subjects (mean age $42.2 \pm 9.9$ years) were analyzed. Mean duration of symptoms was $11.45 \pm 6.6$ months. Average number of leaks per eye was 2.8 and one laser spot per leak was performed. There was complete resolution of subretinal fluid in 15 out of 16 eyes at 2 months. Average visual analog pain scale score was $0.63 \pm 1.41$.

Conclusion: Navilas ${ }^{\circledR}$ without a contact lens achieved resolution of subretinal fluid with a single laser spot for each single leak and minimum iatrogenic damage.

Keywords: navigated laser, Navilas ${ }^{\mathbb{R}}$

\section{Introduction}

Idiopathic central serous chorioretinopathy (CSCR) is characterized by accumulation of fluid resulting in circumscribed elevation of the retina at the posterior pole. ${ }^{1}$ Various theories have been proposed for fluid accumulation including focal imbalance of retinal pigment epithelium ionic transport system, and elevated choroidal pressure. ${ }^{2}$ Most of the cases have self-limiting courses. Treatment for nonresolving CSCR cases is controversial. Maumenee described the concept of a leakage site within the retinal pigment epithelial layer following fluorescein angiographic studies in patients with CSCR. ${ }^{3}$ Since then, laser application to the site of leakage (direct laser photocoagulation) has become a commonly used treatment modality. Laser photocoagulation shortens the duration by 2 months and also reduces the recurrence rate with no change in the final visual outcome. ${ }^{4-7}$

Conventional laser photocoagulation for leak in eyes with CSCR can be a difficult task. Exact localization of the angiographic leaky spot on the live inverted fundus view among the blood vessel crossings on the moving eye can be challenging. Accuracy of the treatment needs to be assessed by repeat fluorescein angiogram. Due to an approximate location on the live fundus view of the leaking spot, multiple laser spots have to be applied even for a single leaking spot. For thermal laser approach, there is a need to improve the accuracy of treatment, reduce the number of burns, and thus, reduce retinal damage.

Recently, navigated laser photocoagulation has improved accuracy and comfort for retinal laser photocoagulation for various retinovascular diseases. ${ }^{8}$ Previous reports have shown that laser photocoagulation using the navigated laser system is safe and 
achieves a higher rate of accuracy (92\%) in photocoagulation than conventional ( $72 \%$ ) laser in treatment of diabetic retinopathy microaneurysms. ${ }^{8}$ Navigated laser photocoagulation using fundus camera platform has many advantages in various respects including treatment duration and pain experience for the patient. ${ }^{9-12}$

We hypothesize that navigated laser, due to its ability of eye tracking and laser planning on the fluorescein angiography image on the same device, can perform precise targeted treatments and, thus, could be a good alternative for conventional manually directed laser photocoagulation in CSCR. There are no studies available that evaluated the role of navigated laser photocoagulation in CSCR. The aim of the study was to assess the efficacy of navigated laser treatment in treatment of CSCR.

\section{Methods}

This noncomparative prospective consecutive interventional case series was performed at the L V Prasad Eye Institute, Hyderabad, India from January 2013 to June 2013. Prior approval from the Institutional Review Board was taken and informed consent was obtained from each study subject. This study was conducted in accordance with the tenets of the Declaration of Helsinki. Inclusion criteria included adults $\geq 18$ years old. Nonresolving CSCR was defined as: persistent CSCR with a duration of 3 months or more; center-involving neurosensory detachment with minimum best-corrected visual acuity (BCVA) of 20/200 or better in the study eye; fellow eye vision loss due to CSCR; and presence of active angiographic leakage in fluorescein angiography. Exclusion criteria included: any previous treatment for CSCR in the study eye; CSCR with subfoveal leak for which laser photocoagulation may not be the treatment of choice; current oral/topical steroid exposure, which may be necessary for any systemic illness; decrease in visual acuity due to causes other than CSCR; history of intraocular surgery in the study eye or anticipated within the next 6 months following day 1 ; prior panretinal laser photocoagulation or macular laser photocoagulation in the study eye; history of allergy to fluorescein used in fluorescein angiography; myopia of more than -6.0 diopters; Cushing's disease; renal diseases; pregnancy and breastfeeding; and inability to obtain fundus photographs or fluorescein angiograms of sufficient quality to be analyzed by the site.

All participants underwent a comprehensive ophthalmic examination including BCVA testing, slit-lamp biomicroscopy, intraocular pressure measurement using Goldmann applanation tonometer, and dilated fundoscopic examination.

\section{Imaging}

Color fundus photographs and fluorescein angiography (FA) was performed at baseline using Navilas ${ }^{\circledR}$ system (OD-OS $\mathrm{GmbH}$, Teltow, Germany). All patients underwent a routine FA procedure with intravenous injection of $5 \mathrm{~mL}$ of a $10 \%$ sodium fluorescein solution (Novartis International AG, Basel, Switzerland). After the injection, images were taken from the early phase (10-20 seconds) to the late phase (10 minutes). From each series, one representative angiogram from the early phase and one from the late phase were selected for analysis.

\section{Spectral-domain optical coherence tomography (SD-OCT)}

SD-OCT images were obtained by a certified technician using the Zeiss Cirrus OCT $^{\circledR}$ (Carl Zeiss Meditec AG, Jena, Germany) device. The scans included a 5-line raster scan pattern and the cube for quantitative measuring. If the automated thickness value was determined to be inaccurate, central retinal thickness (CRT) was measured manually. CRT was defined as the distance from the inner retinal surface to the inner border of the retinal pigment epithelium (RPE).

\section{Laser photocoagulation}

A single physician (JC) performed the treatment planning using the earliest phase of FA on Navilas ${ }^{\circledR}$ system that showed leaking spot. The same physician performed the laser treatment on the same device without using contact lens. Initial test burn was performed away from the macular region to decide the parameters for treatment laser shots. Laser parameters were set as greyish white burn, spot size 70-100 $\mu \mathrm{m}$, and pulse duration $30 \mathrm{~ms}$. Immediately after laser session, central $30^{\circ}$ color fundus photographs were obtained using the Navilas ${ }^{\circledR}$ system for all subjects.

Visual analog scale (VAS) was used to evaluate pain 5 minutes after the laser treatment. The VAS consists of a $10 \mathrm{~cm}$ line, with 0 on one end representing no pain and $10 \mathrm{on}$ the other representing the worst pain ever experienced.

Primary outcome measure was resolution of neurosensory detachment at 2 months of follow-up on SD-OCT. Secondary outcome measures included change in BCVA score at 2 months compared to baseline, change in CRT, number of leaks on FA at baseline, treatment parameters including total number of shots for each leaky spot on early phase FA, average power used, total power used, and posttreatment BCVA; CRT and VAS score for pain experience were also noted. 


\section{Statistical analysis}

Descriptive statistics were calculated for each variable. Visual acuity was converted to logMAR (the logarithm of the minimum angle of resolution) for statistical analysis. Statistical analyses were calculated using Graph Pad Prism 5 (GraphPad Software, Inc., San Diego, CA, USA). To analyze the change in BCVA and CRT at baseline and at 2 months follow-up, paired $t$-test was used. A $P$-value of 0.05 was considered statistically significant.

\section{Results}

A total of 16 eyes of 15 subjects were enrolled for this prospective study. The mean age of patients was $42.2 \pm 9.9$ years with 12 males and three females. Mean duration of symptoms was $11.45 \pm 16.6$ months (range 3 months to 4 years). Clinical characteristics of study subjects are shown in Table 1. The most common location of a leak in relation to the fovea was superonasal (15 leaks, 34\%), inferonasal (13 leaks, $29 \%$ ), superotemporal (10 leaks, 23\%) and inferotemporal (7 leaks, 14\%). Mean pretreatment BCVA and posttreatment BCVA at 2 months was $0.28 \log$ MAR (71 ETDRS [Early Treatment Diabetic Retinopathy Study] letter score, approximately 20/40) and 0.17 logMAR (76.5 ETDRS letters score, approximately $20 / 30)$, respectively $(P=0.171)$.

The average number of leaks per eye was 2.8 , and one laser spot per leak was performed after test burns. Average spot size was $94 \pm 9.48 \mu \mathrm{m}$. Mean power used for each laser spot was $106.1 \pm 32.0 \mathrm{~mW}$. Mean central macular thickness was $337.1 \pm 231.5$ and $165 \pm 61.8 \mu \mathrm{m}$ at baseline and at two months follow-up, respectively, with a statistically significant difference $(P=0.007)$. Complete resolution of subretinal fluid at 2 months of follow-up was noted in 15 out of 16 eyes (94\%). Average VAS score for pain experience was $0.63 \pm 1.41$. A representative case has been shown as Figure 1 .

\section{Discussion}

Medical management, including low-dose aspirin, low-dose methotrexate, finasteride- mineralocorticoid receptor antagonist, have been tried in CSCR, but these did not achieve encouraging results. ${ }^{13-17}$ Various available treatment methods for CSCR include continuous-wave conventional laser thermal photocoagulation, ${ }^{5,6,18}$ photodynamic therapy (PDT), and micropulse diode laser. ${ }^{19-21}$ PDT, although sometimes effective in chronic cases, is costly and can be associated with RPE atrophy and choroidal neovascularization. ${ }^{22}$ Therefore, PDT should be restricted for subfoveal leak and eyes with diffuse RPE leak. Successful treatment using nondamaging subthreshold micropulse laser has been reported in several case-series studies and in a prospective randomized doubleblind sham-controlled pilot trial. ${ }^{19,23-27}$ One of the challenges with micropulse laser is that the physician is unable to assess the laser uptake due to invisible burns. ${ }^{23}$

The mechanism of subretinal fluid resolution after laser photocoagulation treatment is controversial. Proposed mechanisms include the sealing of focal defects in the RPE, promoting a healing response and recruitment of healthy RPE cells, or directly stimulating the pumping function of RPE cells near the leak. ${ }^{6,7,28}$

Various studies have established the role of laser in nonresolving CSCR. Robertson and Ilstrup ${ }^{6}$ showed no recurrences

Table I Clinical characteristics of subjects who underwent navigated laser photocoagulation for central serous chorioretinopathy

\begin{tabular}{|c|c|c|c|c|c|c|c|c|c|c|c|c|}
\hline $\begin{array}{l}\text { Eye } \\
\text { number }\end{array}$ & $\begin{array}{l}\text { Subject } \\
\text { number }\end{array}$ & $\begin{array}{l}\text { Age } \\
\text { (years) }\end{array}$ & Sex & Eye & BCVA & $\begin{array}{l}\text { Duration } \\
\text { of symptoms } \\
\text { (months) }\end{array}$ & $\begin{array}{l}\text { CMT } \\
(\mu \mathrm{m})\end{array}$ & $\begin{array}{l}\text { Number } \\
\text { of laser shots } \\
\text { per leak }\end{array}$ & $\begin{array}{l}\text { Total number } \\
\text { of leaks }\end{array}$ & $\begin{array}{l}\text { Complete } \\
\text { resolution } \\
\text { at } 2 \text { months }\end{array}$ & $\begin{array}{l}\text { BCVA at } \\
2 \text { months }\end{array}$ & $\begin{array}{l}\text { CMT at } \\
2 \text { months } \\
(\mu \mathrm{m})\end{array}$ \\
\hline I & 1 & 34 & $\mathrm{~F}$ & OS & $20 / 25$ & 4 & 148 & $I$ & 4 & Yes & $20 / 20$ & 148 \\
\hline 2 & 2 & 56 & $M$ & OD & $20 / 60$ & 7 & 185 & I & 13 & Yes & $20 / 40$ & 112 \\
\hline 3 & 3 & 49 & $M$ & OS & $20 / 25$ & 3 & 356 & I & 2 & Yes & $20 / 20$ & 312 \\
\hline 4 & 4 & 35 & $M$ & OD & $20 / 25$ & 7 & 319 & I & I & No & $20 / 20$ & 295 \\
\hline 5 & 5 & 43 & $M$ & OD & $20 / 40$ & 48 & 324 & I & 4 & Yes & $20 / 60$ & 72 \\
\hline 6 & 5 & 43 & $M$ & OS & $20 / 30$ & 48 & 140 & I & 3 & Yes & $20 / 40$ & 140 \\
\hline 7 & 6 & 43 & $M$ & OD & $20 / 40$ & 5 & 180 & I & I & Yes & $20 / 40$ & 156 \\
\hline 8 & 7 & 33 & $M$ & OD & $20 / 30$ & 3 & 490 & I & I & Yes & $20 / 20$ & 160 \\
\hline 9 & 8 & 35 & $\mathrm{~F}$ & OD & $20 / 20$ & 3 & $15 \mid$ & I & I & Yes & $20 / 20$ & $|5|$ \\
\hline 10 & 9 & 26 & $M$ & OD & $20 / 60$ & 3 & 526 & I & I & Yes & $20 / 20$ & 152 \\
\hline 11 & 10 & 60 & $M$ & OS & $20 / 160$ & 6 & 287 & I & I & Yes & $20 / 60$ & 166 \\
\hline 12 & 11 & 50 & $M$ & OD & $20 / 60$ & 12 & 263 & I & 3 & Yes & $20 / 40$ & 210 \\
\hline 13 & 12 & 36 & $F$ & OD & $20 / 25$ & 3 & 776 & I & I & Yes & $20 / 20$ & 176 \\
\hline 14 & 13 & 46 & $M$ & OD & $20 / 30$ & 3 & 914 & I & I & Yes & $20 / 20$ & 167 \\
\hline 15 & 14 & 55 & $M$ & OS & $20 / 60$ & 36 & 268 & I & 6 & Yes & $20 / 60$ & 144 \\
\hline 16 & 15 & 31 & $M$ & OD & $20 / 40$ & 3 & 167 & I & 2 & Yes & $20 / 40$ & 120 \\
\hline
\end{tabular}

Abbreviations: BCVA, best-corrected visual acuity; CMT, central macular thickness; F, female; M, male; OD, right eye; OS, left eye. 


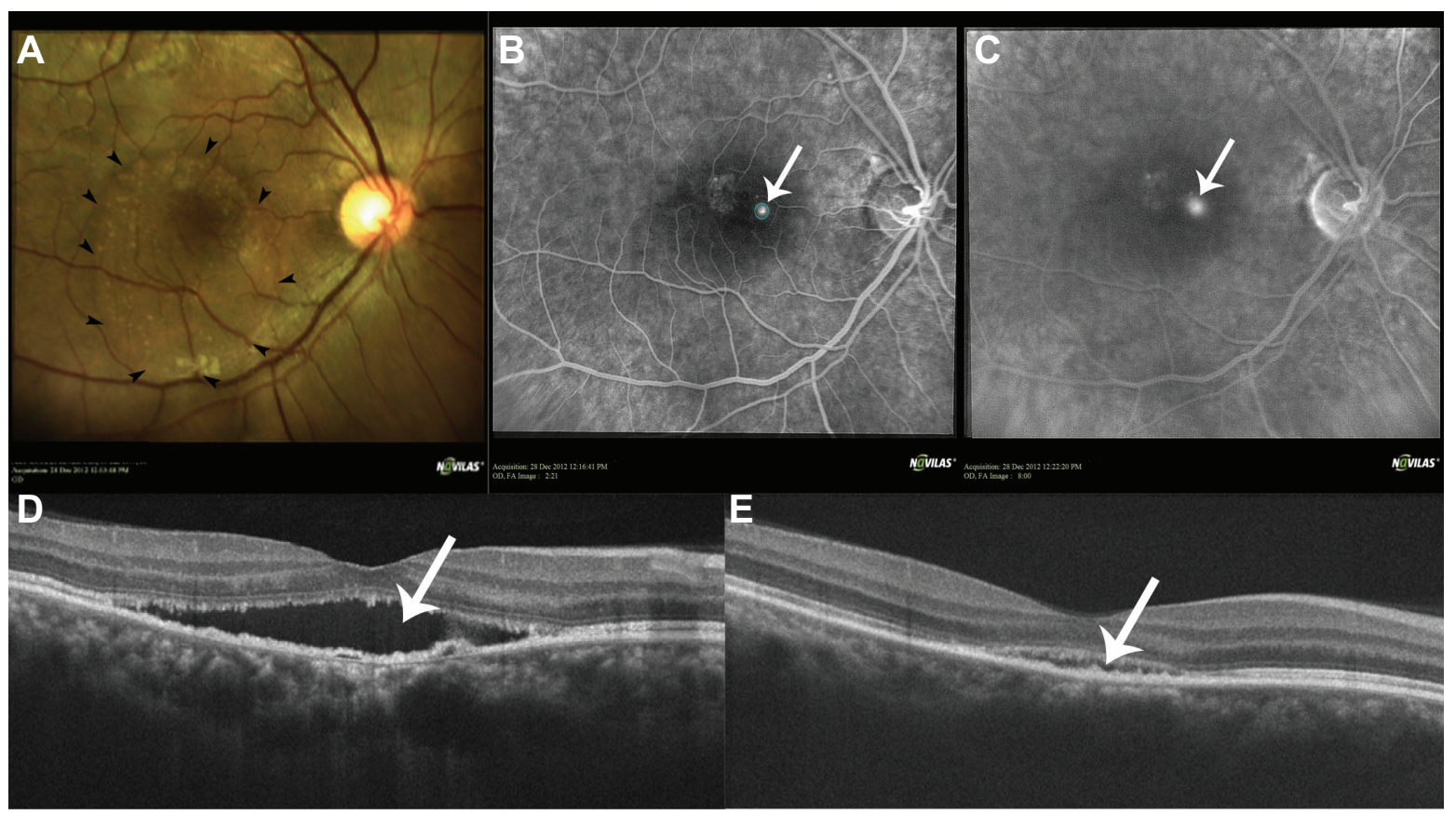

Figure I A 35-year-old male presented with distorted vision in his right eye for the past 7 months.

Notes: (A) The 35-year-old male's best-corrected visual acuity in the right eye was 20/25, with a pocket of subretinal fluid (black arrowheads) seen on the color fundus photograph. (B) Laser photocoagulation was planned as a single laser spot on the leak (blue circle) and was performed with the following parameters: spot size: $70 \mu \mathrm{m}$; power: $70 \mathrm{~mW}$; pulse duration: $30 \mathrm{~ms}$. Fundus fluorescein angiography showed early hyperfluorescence (arrow) suggestive of a leak (blue circle). (C) The hyperfluorescence is increased in the late phase (arrow). (D) SD-OCT showed subretinal fluid (arrow). At 2 months follow-up, his best-corrected visual acuity in the right eye was 20/20, with improvement in his symptoms. (E) SD-OCT showed very shallow subretinal fluid (arrow) with recovery of foveal contour.

Abbreviation: SD-OCT, spectral-domain optical coherence tomography.

in a "direct" laser group at up to 18 months of follow-up. In our study, complete resolution was achieved in 15 out of 16 eyes at 2 months. However, the central macular thickness had significantly reduced in the remaining one eye. A study by Lim et $\mathrm{al}^{29}$ reported resolution of fluid at 1 month after conventional laser in 7 out of 12 eyes; however, all the eyes had resolution of fluid by month 3 .

We experienced no discomfort for the physician or for the patient. The difficulty of finding the leaky spot on the live inverted fundus view through the slit lamp conventional laser device was alleviated by using a navigated laser device. There was no contact lens used and the treatment could be performed in infrared mode, which made patients very comfortable.

As the laser planning is done using early phase of FA, a single laser spot was sufficient for single leaky spot thanks to computerized image guidance, unlike conventional laser where an average of three to five spots are required to successfully target a single leak. ${ }^{7}$ The overall energy used was also reduced, due to the lower number of laser burns. Thus, navigated laser helps reduce retinal damage by targeting the leaky spots and avoiding unnecessary laser photocoagulation.

In our study, we did not find any significant difference between the visual acuity at baseline and after resolution of neurosensory detachment. Similar results were reported from other authors previously. ${ }^{6,18}$ The primary goal of laser photocoagulation is to decrease the time for visual recovery and reduce the recurrence rate, as suggested by Robertson and Ilstrup, ${ }^{6}$ Burumcek et al, ${ }^{18}$ and Watzke et al ${ }^{30}$ However, in our study, a few eyes with a long duration of symptoms showed no improvement in visual acuity, in spite of resolution of fluid.

Very high accuracy $(92 \%)$ of navigated laser in eyes with diabetic macular edema has been reported previously. ${ }^{8}$ Localization and treatment of leak very close to the foveal avascular zone can be comfortably done using the eye tracking feature of navigated laser systems. Laser spot size close to the foveal avascular zone can be reduced by up to $50 \mu \mathrm{m}$ to prevent foveal damage. The smallest laser spot, with minimal pulse duration and a single laser shot for leaky spot, may reduce the chances of central scotoma that are reported with conventional laser. ${ }^{7}$

Limitations of our study include small sample size and no control group. We did not perform fluorescein angiography to rule out any leakage at 2 months; however, SD-OCT, being a noninvasive diagnostic modality, was used to assess the response to treatment. Our study included eyes with focal leakage, but did not include eyes with diffuse angiographic leakage; therefore, these results cannot be applied to eyes with diffuse leakage. 


\section{Conclusion}

In conclusion, navigated laser photocoagulation achieves complete resolution of neurosensory detachment with a single laser spot for each leaking spot in CSCR. Laser planning and treatment on the computer screen, as well as the lack of use of contact lenses, makes navigated laser a preferred option for laser photocoagulation in CSCR. Future studies comparing navigated laser to conventional laser with long-term follow up are warranted.

\section{Disclosure}

The authors report no conflicts of interest in this work.

\section{References}

1. Gass JD. Pathogenesis of disciform detachment of the neuroepithelium. Am J Ophthalmol. 1967;63(3):Suppl:1-139.

2. Marmor M. On the cause of serous detachments and acute central serous chorioretinopathy. Br J Ophthalmol. 1997;81(10):812-813.

3. Maumenee AE. Macular Diseases: Clinical Manifestations. Trans Am Acad Ophthalmol Otolaryngol. 1965;69:605-613.

4. Ficker L, Vafidis G, While A, Leaver P. Long-term follow-up of a prospective trial of argon laser photocoagulation in the treatment of central serous retinopathy. Br J Ophthalmol. 1988;72(11):829-834.

5. Leaver P, Williams C. Argon laser photocoagulation in the treatment of central serous retinopathy. Br J Ophthalmol. 1979;63(10): 674-677.

6. Robertson DM, Ilstrup D. Direct, indirect, and sham laser photocoagulation in the management of central serous chorioretinopathy. Am J Ophthalmol. 1983;95(4):457-466.

7. Verma L, Sinha R, Venkatesh P, Tewari HK. Comparative evaluation of diode laser versus argon laser photocoagulation in patients with central serous retinopathy: a pilot, randomized controlled trial [ISRCTN84128484]. BMC Ophthalmol. 2004;4:15.

8. Kozak I, Oster SF, Cortes MA, et al. Clinical evaluation and treatment accuracy in diabetic macular edema using navigated laser photocoagulator NAVILAS. Ophthalmology. 2011;118(6):1119-1124.

9. Kozak I, Kim JS, Oster SF, Chhablani J, Freeman WR. Focal navigated laser photocoagulation in retinovascular disease: clinical results in initial case series. Retina. 2012;32(5):930-935.

10. Chhablani J, Kozak I, Barteselli G, El-Emam S. A novel navigated laser system brings new efficacy to the treatment of retinovascular disorders. Oman J Ophthalmol. 2013;6(1):18-22.

11. Neubauer AS, Langer J, Liegl R, et al. Navigated macular laser decreases retreatment rate for diabetic macular edema: a comparison with conventional macular laser. Clin Ophthalmol. 2013;7:121-128.

12. Ober MD, Kernt M, Cortes MA, Kozak I. Time required for navigated macular laser photocoagulation treatment with the Navilas. Graefes Arch Clin Exp Ophthalmol. 2013;251(4):1049-1053.

13. Breukink MB, den Hollander AI, Keunen JE, Boon CJ, Hoyng CB. The use of eplerenone in therapy-resistant chronic central serous chorioretinopathy. Acta Ophthalmol. Epub 2014.

Clinical Ophthalmology

\section{Publish your work in this journal}

Clinical Ophthalmology is an international, peer-reviewed journal covering all subspecialties within ophthalmology. Key topics include: Optometry; Visual science; Pharmacology and drug therapy in eye diseases; Basic Sciences; Primary and Secondary eye care; Patient Safety and Quality of Care Improvements. This journal is indexed on
14. Caccavale A, Romanazzi F, Imparato M, et al. Low-dose aspirin as treatment for central serous chorioretinopathy. Clin Ophthalmol. 2010; 4:899-903.

15. Mazzolani F, Togni S. Oral administration of a curcumin-phospholipid delivery system for the treatment of central serous chorioretinopathy: a 12-month follow-up study. Clin Ophthalmol. 2013;7:939-945.

16. Kurup SK, Oliver A, Emanuelli A, Hau V, Callanan D. Low-dose methotrexate for the treatment of chronic central serous chorioretinopathy: a retrospective analysis. Retina. 2012;32(10):2096-2101.

17. Forooghian F, Meleth AD, Cukras C, et al. Finasteride for chronic central serous chorioretinopathy. Retina. 2011;31(4):766-771.

18. Burumcek E, Mudun A, Karacorlu S, Arslan MO. Laser photocoagulation for persistent central serous retinopathy: results of long-term follow-up. Ophthalmology. 1997;104(4):616-622.

19. Gupta B, Elagouz M, McHugh D, Chong V, Sivaprasad S. Micropulse diode laser photocoagulation for central serous chorio-retinopathy. Clin Experiment Ophthalmol. 2009;37(8):801-805.

20. Roider J, Brinkmann R, Wirbelauer C, Laqua H, Birngruber R. Subthreshold (retinal pigment epithelium) photocoagulation in macular diseases: a pilot study. Br J Ophthalmol. 2000;84(1):40-47.

21. Elsner H, Porksen E, Klatt C, et al. Selective retina therapy in patients with central serous chorioretinopathy. Graefes Arch Clin Exp Ophthalmol. 2006;244(12):1638-1645.

22. Moon JW, Yu HG, Kim TW, Kim HC, Chung H. Prognostic factors related to photodynamic therapy for central serous chorioretinopathy. Graefes Arch Clin Exp Ophthalmol. 2009;247(10):1315-1323.

23. Chen SN, Hwang JF, Tseng LF, Lin CJ. Subthreshold diode micropulse photocoagulation for the treatment of chronic central serous chorioretinopathy with juxtafoveal leakage. Ophthalmology. 2008;115(12):2229-2234.

24. Koss MJ, Beger I, Koch FH. Subthreshold diode laser micropulse photocoagulation versus intravitreal injections of bevacizumab in the treatment of central serous chorioretinopathy. Eye (Lond). 2012;26(2):307-314.

25. Lanzetta P, Furlan F, Morgante L, Veritti D, Bandello F. Nonvisible subthreshold micropulse diode laser $(810 \mathrm{~nm})$ treatment of central serous chorioretinopathy. A pilot study. Eur J Ophthalmol. 2008;18(6):934-940.

26. Ricci F, Missiroli F, Regine F, Grossi M, Dorin G. Indocyanine green enhanced subthreshold diode-laser micropulse photocoagulation treatment of chronic central serous chorioretinopathy. Graefes Arch Clin Exp Ophthalmol. 2009;247(5):597-607.

27. Roisman L, Magalhães FP, Lavinsky D, et al. Micropulse diode laser treatment for chronic central serous chorioretinopathy: a randomized pilot trial. Ophthalmic Surg Lasers Imaging Retina. 2013;44(5):465-470.

28. Klatt C, Saeger M, Oppermann T, et al. Selective retina therapy for acute central serous chorioretinopathy. $\mathrm{Br} J$ Ophthalmol. 2011;95(1):83-88

29. Lim JW, Kang SW, Kim YT, Chung SE, Lee SW. Comparative study of patients with central serous chorioretinopathy undergoing focal laser photocoagulation or photodynamic therapy. $\mathrm{Br} J$ Ophthalmol. 2011;95(4):514-517.

30. Watzke RC, Burton TC, Leaverton P. Ruby laser photocoagulation therapy of central serous retinopathy. A preliminary report. Mod Probl Ophthalmol. 1974;12(0):242-246.

PubMed Central and CAS, and is the official journal of The Society of Clinical Ophthalmology (SCO). The manuscript management system is completely online and includes a very quick and fair peer-review system, which is all easy to use. Visit http://www.dovepress.com/ testimonials.php to read real quotes from published authors. 